\title{
Effects of Internet Addiction on Work Place Productivity: With Special Reference to Alacrity in Nagpur
}

\author{
${ }^{1}$ Dr. Monika R Seth, ${ }^{2}$ Mr. Atharva R Karpate, ${ }^{3}$ Mr. Abhinav Bathula \\ ${ }^{1,2,3}$ Assistant Professor, Department of Humanities, Shri Ramdeobaba College of Engineering and Management \\ Email:sethmr@rknec.edu,karpatear@rknec.edu,bathulaa@rkenc.edu
}

\section{Received: $20^{\text {th }}$ September 2018, Accepted: $11^{\text {th }}$ October 2018, Published: $31^{\text {st }}$ October 2018}

\begin{abstract}
Addiction is defined as a compulsive need for and use of a habit-forming substance characterized by tolerance and well-defined physiological symptoms upon withdrawal. With the onset of the internet and the subsequent widespread ease of access to it, the average human life has been deeply impacted and affected by it. This is evident and characterized by the gradual but definite inculcation of the internet into the daily lives of human beings, so much so that addiction to the internet is recognized as a legitimate and booming mental disorder by World Health Organization.

The present age group of 20-30 years has been raised with the internet as a very integral and substantial informative source in their upbringing. Considering how this age group is of employable age and seeks jobs, it becomes of utmost relevance to study internet addiction disorder and to find out its effects and implications in job productivity, keeping in mind the unquestionable role of internet to carry out daily functions of an average work environment. Thus, the paper aims to find out the effect of internet addiction on workplace productivity in Alacrity (BPO) located in city of Nagpur.

Sales reports and performance linked incentive (PLI) reports were collected for 100 employees working in BPO sector, aged between 18-28. The data thus collected was tabulated in the form of daily internet usage and PLI earned, over a period of one year for fiscal year 2017-18. The data was collected through telephonic conversation.

After studying the tabulated data of Internet usage and PLI earned, it was concluded that the average PLI earned by the employees decreased with the subsequent substantial increase in the internet usage amongst employees in the fiscal year 2017-18.
\end{abstract}

\section{Keywords}

Internet Addiction, Work Place Productivity, Physiological Symptoms, Work Environment, Performance Linked Incentive (PLI)

\section{Introduction}

In this 21 st century, using the Internet at the workplace is not only unavoidable but essential to business success. With widespread connectivity and constantly emerging tantalizing online activities, people are spending more and more time online for studying, learning, communicating, creating, and entertaining themselves. The Economic Times reported, the number of Internet users stood at 481 million in December 2017, an increase of $11.34 \%$ over December 2016 in the report titled, "Internet in India 2017." However, very few people are able to compartmentalize and use the internet without letting it affect their productivity. There is a fine line between healthy use and problematic use, which is getting blurred these days. And the purpose of this study is to establish a strong demarcation between the healthy and addictive use of internet.

\section{Key Definitions}

- Internet Addiction: Internet addiction refers to the excessive use or pathological use that interferes with daily life. It is described as an impulse control disorder, which does not involve use of an intoxicating drug and is very similar to pathological gambling.

- Workplace productivity: It is an assessment of the efficiency of a worker or a group of workers. It is usually evaluated in terms of the output of the employee in a specific period of time.

- Work Environment: Work environment is used to describe the surrounding conditions in which an employee operates. They include office conditions, temperature, equipment etc. and also relates to factors such as work processes or procedures.

- Performance Linked Incentive: Performance Linked Incentive (PLI) is a form of payment from an employer to employee, which is directly related to the performance output of an employee for a specific period of time.

- Cyberloafing: Cyberloafing is a term used to describe actions of employees who use their internet access for personal use while pretending to do legitimate work. 


\section{Review of Literature}

Review of journals online and print have revealed that many studies have been previously conducted to study addiction of internet among various demography of population such as high school students, employees and graduate professionals. Review of this literature has helped in identifying key processes and techniques in order to obtain a result as free of error as possible.

1.Mohammadkhani P, Alkasir E, Pourshahbaz A, Jafarian Dehkordi F, Soleimani Sefat E. Internet Addiction in High School Students and Its Relationship with the Symptoms of Mental Disorders. Iranian Rehabilitation Journal. $\quad 2017 ; \quad 15(2): 141-\quad 148 . \quad$ https://doi.org/10.18869/NRIP.IRJ.15.2.141: https://doi.org/10.18869/NRIP.IRJ.15.2.141

2. Goel D, Subramanyam A, Kamath R. A study on the prevalence of internet addiction and its association with psychopathology in Indian adolescents. Indian Journal of Psychiatry. 2013;55(2):140-143. doi:10.4103/00195545.11145

3. Apoorva Shrivastava, Manoj K. Sharma, and P. Mari Muthu. Internet use at workplaces and its effects on working style in Indian context: An exploration. Indian Journal of Occupational \& Environmental Medicine. PMCID: PMC5299818, PMID: 28194082

4. Recommended Citation Galletta, Dennis F. and Poliak, Peter, "An Empirical Investigation of Antecedents of Internet Abuse in the Workplace" (2003). SIGHCI 2003 Proceedings. 14. http://aisel.aisnet.org/sighci2003/14

\section{Hypothesis}

There is a significant correlation between internet usage and job productivity at a BPO workplace.

\section{Materials and Methods}

The aim of the study was to assess the pattern of internet addiction at a workplace and its effects on job productivity. A sample of 100 participants were analyzed during the study. Sales reports and performance linked incentive (PLI) reports were collected for these 100 employees working in BPO sector, aged between 18-28 for fiscal year 2017-18. The data was collected through google forms and telephonic conversations. To test internet addiction amongst employees Internet Addiction Test (IAT) by Dr. Kimberly Young was administered.

Internet Addiction Test (IAT) by Dr. Kimberly Young

Internet Addiction Test (IAT) by Dr. Kimberly Young. Internet Addiction Test (IAT) is a reliable and valid measure of addictive use of Internet, developed by Dr. Kimberly Young. It consists of 20 items that measures mild, moderate and severe level of Internet Addiction. Each Question can be answered in one of the five ways by the participants provided by the scale.

Sample questions: -

1. How often do you find that you stay on-line longer than you intended?

2. How often do others in your life complain to you about the amount of time you spend on-line?

3. How often do you check your email before something else that you need to do?

4. How often do you choose to spend more time on-line over going out with others?

5. How often do you feel depressed, moody or nervous when you are off-line, which goes away once you are back on-line?

Scale: -

\begin{tabular}{|l|l|}
\hline 0 & Does not apply \\
\hline 1 & Rarely \\
\hline 2 & Occasionally \\
\hline 3 & Frequently \\
\hline 4 & Often \\
\hline 5 & Always \\
\hline
\end{tabular}

Total up the scores for each item. The higher the score, the greater level of addiction is.

1. $20-49$ points: The participant is an average on-line user. Sign of control usage

2. $50-79$ points: Participant is experiencing occasional or frequent problems because of the Internet.

3. $80-100$ points: Participant registers high internet usage.

\section{Result and Discussion}

This study attempted to examine the extent to which employees engage in Internet abuse at workplace and examine the percentage of addicts for the given sample space. Examining the results from Youngs' IAT test reveals that around $76.7 \%$ of the participants stayed longer than intended on the internet during the work hours. 
$41.6 \%$ of the participants reported delay in meeting their targets directly influenced by the use of internet at workplace. All the participants reported accessing the internet at least once for personal use during the work hours every day. $55.7 \%$ of the employees feel internet directly affects their job productivity. The following graphs and charts correlate key factors considered.

\section{Graphs and Charts}

1. The following pie chart divides the participants into three categories of internet users based on their internet usage-Mild, Moderate and Severe.

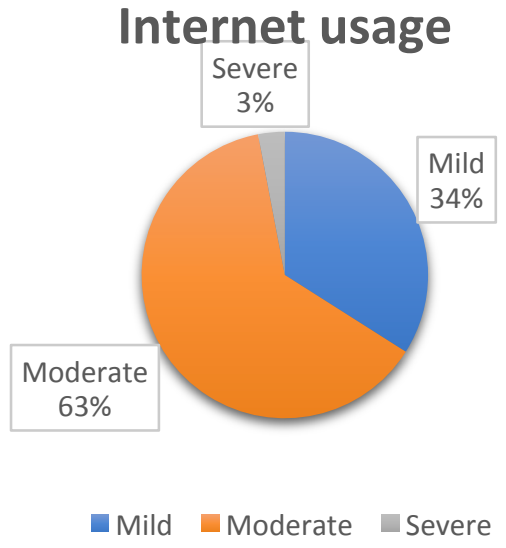

2. The following bar graph shows the incentive earned by the three groups of internet users in the fiscal year 2017-18.

\section{PLI VS INTERNET USAGE}

Average PLI

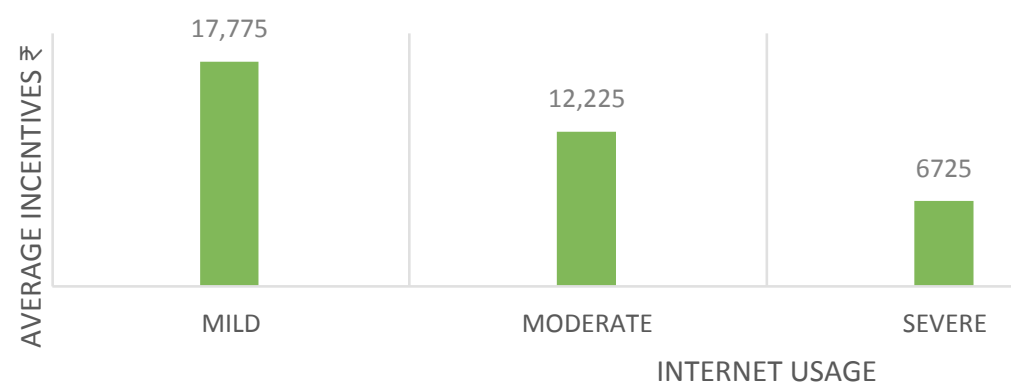

3. The following grap plots the incentive earned with the Youngs' IAT scores.

PLI VS IAT SCORE

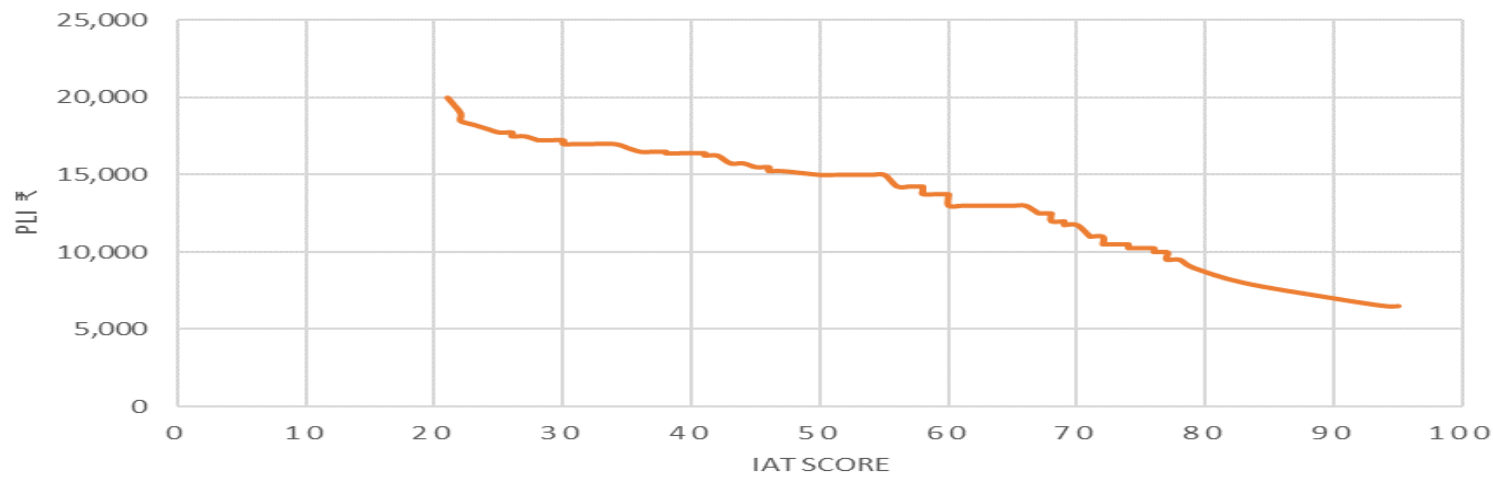


The average Performance linked incentive (PLI) data collected through telephonic conversations for 100 employees in the BPO sector was plotted against their respective IAT test scores.

To study further the relation between internet misuse at workplace; performance linked incentives were considered with Youngs' IAT test score by categorizing results obtained into three categories of users - mild, moderate and severe. It was found that -

1. 34\% were low or mild users who were more recent users of internet and used it for basic purposes like checking emails, reading news, occasional online shopping- averaging about an hour. These employees are not involved in cyberloafing and drew an above average PLI.

2. $63 \%$ users were found to be moderate users who used the internet for social media, online media, online gaming and browsing averaging to 2.5-3 hours a day. The PLI drawn shows a dip comparatively but cyberloafing did not affect job productivity.

3. $3 \%$ users were found to be severe users or "internet addicts" who used internet for more than 6 hours a day. This happened through consistent and continuous checking of messaging inbox, to excessive online gaming and "binge-watching" of online media. This group showed a major dip in PLI drawn and cyberloafing resulted in a sharp decline in job productivity.

\section{Limitations}

The sample data for the study was collected from Nagpur city only. Participants were sourced majorly from Alacrity and few other BPOs (Business Process Organisation), which limited the professional diversity and the quantity of the sample space considered. Other factors such as environmental factors as well as personality types were not taken into consideration. Also, mental health of the participants was not ascertained.

\section{Conclusions}

The results confirmed that there isn't a significant co-relation between internet addiction and its effects on job productivity. Only $3 \%$ of the total participants were found to be possible addicts to the internet and showed effects on job productivity. This was confirmed through PLI data collected. Majority of the employees were reported to be moderate users of the internet and showed low or no loss in their job productivity. No significant difference in the PLI drawn was observed between mild and low users.

\section{References}

1. Mohammadkhani P, Alkasir E, Pourshahbaz A, Jafarian Dehkordi F, Soleimani Sefat E. Internet Addiction in High School Students and Its Relationship with the Symptoms of Mental Disorders. Iranian Rehabilitation Journal. 2017; 15(2):141- 148. https://doi.org/10.18869/NRIP.IRJ.15.2.141: https://doi.org/10.18869/NRIP.IRJ.15.2.141

2. Goel D, Subramanyam A, Kamath R. A study on the prevalence of internet addiction and its association with psychopathology in Indian adolescents. Indian Journal of Psychiatry. 2013;55(2):140-143. doi:10.4103/0019-5545.11145

3. Apoorva Shrivastava, Manoj K. Sharma, and P. Mari Muthu. Internet use at workplaces and its effects on working style in Indian context: An exploration. Indian Journal of Occupational \& Environmental Medicine. PMCID: PMC5299818, PMID: 28194082

4. Recommended Citation Galletta, Dennis F. and Polak, Peter, "An Empirical Investigation of Antecedents of Internet Abuse in the Workplace" (2003). SIGHCI 2003 Proceedings. 14. http://aisel.aisnet.org/sighci2003/14

5. Young KS. Internet addiction: The emergence of a new clinical disorder. Cyberpsychology Behaviour. 1998; 1:237-44. 